\title{
African American Pastors on Mental Health, Coping, and Help Seeking
}

By: Janeé R. Avent, Craig S. Cashwell, and Shelly Brown-Jeffy.

Avent, J., Cashwell, C. S., \& Brown-Jeffy, S. (2015). African American pastors on mental health, coping, and help-seeking. Counseling and Values, 60, 32-47.

"This is the peer reviewed version of the following article: Avent, J., Cashwell, C. S., \& Brown-Jeffy, S. (2015). African American pastors on mental health, coping, and helpseeking. Counseling and Values, 60, 32-47, which has been published in final form at http://dx.doi.org/ 10.1002/j.2161-007X.2015.00059.x. This article may be used for noncommercial purposes in accordance with Wiley Terms and Conditions for Self-Archiving."

\begin{abstract}
:
Within the Black Church, there remains much that is unknown about pastoral motivations, beliefs, and attitudes about mental health. The purpose of this study was to investigate pastors' responses to parishioners dealing with mental health issues, including perspectives on counseling services and coping strategies. According to this study's findings, African American pastors often are the first line of support for parishioners' mental health and recognizing adaptive and maladaptive forms of coping.
\end{abstract}

Keywords: African Americans | help seeking | counseling

\section{Article:}

African Americans' mental health is greatly affected by the social (e.g., homelessness, unemployment) and physical health issues (e.g., HIV/AIDS) that plague many African American communities. Accordingly, researchers should direct more careful attention toward the mental health issues, help-seeking behaviors, and various counseling services used by African Americans (U.S. Department of Health and Human Services, 2001, 2010). However, one of the challenges researchers face in determining accurate mental health prevalence data for African Americans is the disparity in the rates of formal help-seeking behaviors that exist between African Americans and other racial and ethnic groups (Buser, 2009).

Compared to majority racial and ethnic groups, minority populations, such as African Americans, are less likely to seek mental health help from counseling professionals (Ayalon \& Young, 2005). In fact, race is a better predictor of help-seeking behaviors than finances or education level (Youman, Drapalski, Steuwig, Bagley, \& Tangney, 2010). Only 15.7\% of all African Americans diagnosed with a mood disorder seek help from a mental health specialist. Furthermore, only $12.6 \%$ of African Americans diagnosed with anxiety disorders seek mental health services (U.S. Department of Health and Human Services, 2001). When African Americans have unmet mental health needs, they are less likely to attain an overall positive measure of well-being (U.S. Department of Health and Human Services, 2001), possibly contributing, at least to some extent, to the social struggles in African American communities (Youman et al., 2010). 
Some of the barriers to African Americans' mental health help-seeking behaviors include stigma (Awosan, Sandberg, \& Hall, 2011), denial of symptomatology, an external locus of control regarding their health (Andrews, Stefurak, \& Mehta, 2011; Ayalon \& Young, 2005), preference for an African American counselor (Awosan et al., 2011; Townes, Chavez-Korrell, \& Cunningham, 2009), alternative beliefs about the etiology of mental health issues (Farris, 2006), cultural norms in African American communities (Awosan et al., 2011), and cultural mistrust (Townes et al., 2009). These barriers may be more prevalent for African Americans living in rural areas (Murry, Heflinger, Suiter, \& Brody, 2011), which is troubling, because most African Americans reside in rural areas of the southern United States (U.S. Department of Health and Human Services, 2001). Local churches and spiritual leaders are alternative resources to traditional mental health care within African American communities. Generally, the church is considered a less stigmatized place for African Americans to receive help (Andrews et al., 2011) and a solution for many mental health problems (Newhill \& Harris, 2007).

Religion and spirituality are recognized not only as alternative coping resources within African American communities, but also as protective factors against anxiety, depression (Mitchell \& Ronzio, 2011), and grief (Laurie \& Neimeyer, 2008; Smith, 2002). Accordingly, researchers have suggested that future studies focus more in depth on African American spirituality and religion (Mitchell \& Ronzio, 2011). Nearly 80\% of African Americans identify religion as an important part of their lives, and 50\% attend church at least weekly; a strong majority practice within the Christian tradition, and 59\% of African Americans report being affiliated with the Black Church (Pew Research Center, 2009).

The Black Church is defined as a Protestant "multitudinous community of churches, which are diversified by origin, denomination, doctrine, worshipping culture, spiritual expression, class, size, and other less obvious factors" (Douglas \& Hopson, 2001, p. 96). The Black Church has been the place where the public and private lives of African Americans intersect (Pinn, 2010), an atmosphere for therapeutic change (Gilkes, 1980), and a gateway into the lives of many African Americans (Watson et al., 2003).

Pastors continue to be a pillar of the Black Church (Lincoln \& Mamiya, 1990). Often, African Americans choose their spiritual leaders as resources for their mental health needs over formal helping resources, such as professional counselors (Ayalon \& Young, 2005; U.S. Department of Health and Human Services, 2001). In the Black Church, pastors are valued as credible sources of assistance with social and psychological problems because of their status as pastors, often regardless of their educational background, knowledge of mental health issues, and previous experience (Kane \& Green, 2009). Furthermore, researchers found that African Americans receive varied messages from pastors regarding their mental health, which, in turn, affects their proclivity for seeking professional help (Newhill \& Harris,2007).

Much remains to be known about pastors' beliefs and influence on the help-seeking behaviors of those in their care. Accordingly, the purpose of this study was to investigate African American pastors' responses to parishioners dealing with various mental health issues; motivations to encourage or discourage help seeking outside of the Black Church; perspectives on secular mental health services in their community; perspectives on spiritual, biological, psychological, 
and social coping methods; and beliefs about identifying and responding to adaptive and maladaptive religious coping strategies. To that end, the research questions were: (a) How often do African American pastors have congregation members disclose mental health issues? (b) How do African American pastors respond (behaviorally) to congregation members who seek their counsel on issues? (c) What factors influence African American pastors' decision to refer members of their church to seek mental health services outside of the church? (d) How do African American pastors perceive mental health service delivery in their community? (e) Do African American pastors encourage religious coping behaviors that neglect or recognize biological, psychological, or social factors? (f) How do African American pastors apportion anxiety and depression across biological, social, psychological, and spiritual spheres of influence?

\section{Method}

We chose consensual qualitative research (CQR) as the methodology because of the research questions and the scarcity of empirical research on this topic (Banyard \& Miller, 1998; Hill, 2012). CQR is a methodology that philosophically falls between a postpositivist and constructivist paradigm (Hays \& Wood, 2011; Williams \& Morrow, 2009) by allowing the researcher to approach the subject matter with some inherent structure while remaining open to the participants' perspectives and new ideas developed along the way (Stahl, Taylor, \& Hill, 2012). Qualitative approaches are particularly fit for contributing to knowledge related to diversity issues (Banyard \& Miller, 1998), which is applicable to this study because the population of interest is from a racial/ethnic minority group.

\section{Participants}

We included African American senior pastors of predominately African American congregations as the population of interest for this study because of their experience with the subject matter (Heppner \& Heppner, 2004). For this study, we defined senior pastors as ministerial leaders of a Protestant church who have been ordained by an authority in their faith communities (Payne, 2009). The institutional review board at the University of North Carolina at Greensboro granted approval for the study. We used purposive and snowball sampling to recruit participants. The first author sent out an initial personalized e-mail to each potential participant that included information about the research study (e.g., approximate time commitments, confidentiality procedures). No more than three invitations were sent to potential participants to avoid unfairly burdening, harassing, or pressuring anyone (Hill \& Williams, 2012). Participants signed an informed consent at the time of the interview.

The sample included eight participants, which is considered appropriate in CQR to allow for consistency and discrepancy (Hill, Thompson, \& Williams, 1997). We assigned participants pseudonyms to protect their identity. Participants (see Table 1) ranged in age from 28 to 69 years $(M=41, S D=14.21)$. Luther, James, Felicia, and William pastored in urban areas; and Jimmy, Scott, and Tyler pastored in more rural areas. Thomas pastored two churches, one located in a more urban area and the other in a more rural area. Participants' (see Table 1) years of pastoral experience ranged from 2 to 37 years $(M=16.00, S D=11.88)$. Seven of the participants identified as male, and one participant identified as female. The participants pastored churches that ranged in size from 72 members to 4,200 members $(M=857.13, S D=1,399.49, M d n=325)$. 
Luther, Felicia, and Jimmy identified as nondenominational; James, Thomas, and Scott identified as Baptist; William identified as Full-Gospel; and Tyler identified as Holiness. Jimmy held a high school diploma; Luther and Tyler had attended some college; James, Felicia, and William held bachelor's degrees; Scott had a master's degree; and Thomas had a doctorate degree.

Table 1. Participant Descriptive Statistics

\begin{tabular}{lrrrrr}
\hline Variable & Range & Min & Max & $M$ & SD \\
\hline Experience (in years) & 35 & 2 & 37 & 16.00 & 11.88 \\
Age & 41 & 28 & 69 & 51.88 & 14.21 \\
Number of members & 4,128 & 72 & 4,200 & 857.13 & $1,399.49$ \\
\hline$\quad$ Note. $N=8$. Min = minimum; Max = maximum. & & & & \\
\hline
\end{tabular}

\section{Research Team}

The research team included two African American women and one Caucasian man. Two of the team members had previous experience with CQR. Additionally, an external auditor, who was an African American woman, was vital to this particular study; she helped to review interview questions and provided feedback during the analysis process. Before beginning the data collection, each member of the research team and the auditor completed a bracketing exercise that listed biases, expectations, history with the Black Church, familiarity with the CQR procedure, racial dynamics, and any other reflections that may have influenced the process. Some of the major themes that emerged from this process included the following: (a) each member was affiliated with academia, (b) two of the research team members and the auditor had significant familiarity with the Black Church, and (c) the members of the research team considered counseling beneficial.

For this study, the research team was a "set team" rather than a rotating team, meaning all team members read each of the interviews, and no members were added during the course of the research project (Hill et al., 2005). We met initially to complete the bracketing exercise and develop and review the research questions. Then, we met three additional times to analyze the data. The data analysis meetings ranged from 1 to 3 hours.

\section{Procedure}

We followed a well-established CQR protocol (Hill et al., 1997). Accordingly, the following is a detailed account of the process for this study at sufficient depth to support replication of the study (Crook-Lyon, Goates-Jones, \& Hill, 2012). For more information about CQR, refer to Hill et al. (1997, 2005). For this study, the first author used a semistructured interview to collect data from the participants (Hill, 2012). The interview questions were a mixture of background, behavioral, opinion, and knowledge questions (Heppner, Wampold, \& Kivlighan, 2008). The questions included the following: (a) Tell me about your background pastoring in the Black Church. (b) Churches are different and have different ways of balancing the salvation message and social justice message. How would you describe how you balance the two? (c) How often do you see individual congregation members facing issues such as anxiety, depression, relationship issues, bereavement, and unemployment? (d) How do you respond to a member who seeks your 
guidance during traumatic events (i.e., anxiety/depression, bereavement, parenting issues, relationship difficulty/divorce, unemployment/financial concerns) and stressors? (e) As a pastor, what is the most challenging part for you in attending to the mental health concerns of your congregation members? (f) What percentage of anxiety and depression do you attribute to biology, psychology, social, and spiritual factors? (g) Could you provide an example of a time when a congregation member who had been struggling with an issue used religion as a support that helped them through that time? Can you give me an example of a time when you saw someone use their religion in a way that ultimately did not help them? (h) What are some of your positive and negative experiences with mental health care providers in your community? (i) Have you or someone close to you ever struggled with these feelings of anxiety and/or depression?

We limited the number of questions to nine so that the interview might be limited to approximately 60 minutes (Burkard, Knox, \& Hill, 2012). Actual interview times ranged from 35 to 75 minutes $(M=53, S D=16.24)$. Participants completed a demographic questionnaire at the interview that included questions about age, gender, relationship status, denominational affiliation, number of church members, geographic region, number of years as a pastor, and education level and degree. Some of these variables have been found to influence clergy behaviors and attitudes toward mental health (Payne, 2008, 2009).

The first author sent participants a copy of their transcript. Participants were encouraged to notify the researcher if it was not an accurate reflection of their words (Freeman, deMarrais, Preissle, Roulston, \& St. Pierre, 2007). None of the participants contacted the researcher and said their transcript was inaccurate. Thus, we began the data analysis process by creating domains. By using this inductive approach, we remained immersed in the data as each member individually reviewed the transcripts, created a proposed domain list, and presented his or her list to other team members during a meeting for discussion. Thus, some original domains changed throughout the analysis process as we reached consensus (Thompson, Vivino, \& Hill, 2012). After this was completed, the auditor reviewed the transcripts and domains. She did not recommend any changes to the domain list. The finalized list included six domains.

After each individualized case was analyzed, we proceeded to cross-analysis. We extrapolated core ideas, created from the raw data within each domain, to paraphrase the participant's words in a concise, universal language (Thompson et al., 2012). We grouped the core ideas together and labeled them as general, typical, or variant. We considered a category general if it included data from seven to eight participants (see Table 2). If half of the participants had the same idea, then we considered it typical (Ladany, Thompson, \& Hill, 2012). If an idea existed in only two to three of the interviews, however, then we considered it variant (Hill et al., 1997; Ladany et al., 2012; Welch,2010). We monitored the frequency count to ensure that all categories were not variant or general (Ladany et al., 2012). Variant responses are discussed in the text and not included in Table 2 because of space limitations. As we made adjustments for individual case analysis based on feedback from the auditor, we also reviewed auditor feedback and made appropriate changes during the cross-analysis (Hill,2012). 
Table 2. General and Typical Categories

\begin{tabular}{lc}
\hline General & Typical \\
\hline Frequency & Type \\
Positive experiences & Stigma \\
Resources & History \\
Complex (coping) & Negative experiences \\
Adaptive coping & Spiritual (coping) \\
Maladaptive coping & Social (coping) \\
Personal experiences & Avoidance \\
& Spiritual (causes) \\
& Social (causes) \\
\end{tabular}

Note. General $=$ seven to eight participants; Typical $=$ four to six participants.

Trustworthiness has been used to describe the validity of qualitative studies (Williams \& Hill, 2012) and is an important aspect of qualitative procedures. We used various methods to maximize trustworthiness, including field notes, an audit trail, a research team, member checking, and a thick description of the data in the Results section (Hays \& Singh, 2011). A significant part of trustworthiness in qualitative research is that the study would benefit a group's well-being (Williams \& Morrow, 2009). In this study, the ability to learn more about how African American pastors provide services could greatly improve mental health services for African Americans.

\section{Results}

Six domains emerged through the analysis process. The domains included: (a) frequency/type of mental health issues, (b) causes of mental health issues, (c) coping with mental health issues, (d) perspectives on mental health services, (e) African American experience, and (f) on being a pastor.

\section{Frequency/Type of Mental Health Issues}

All of the participants responded that they were confronted with mental health issues from their congregants. In fact, seven out of eight of the participants noted they dealt with various mental health issues in their congregations every day, formally (e.g., counseling sessions) and informally (e.g., text messages). Some of the participants also added that these conversations were not necessarily initiated by the congregants and often were manifested in more implicit rather than explicit methods. For example, Tyler stated, "You see it every day. ... You hear it in the testimony."

Along with frequency, five of the participants devoted time to specifying the various types of mental health issues they observed. James stated, "I've dealt with [in] my tenure here, people with schizophrenia, paranoid schizophrenia, autism, and those types of issues. But depression and anxiety are the ones that hit us the most." Furthermore, Thomas added that he has observed "abuse, domestic violence, addictions." Some participants referenced mental health issues or 
distress experienced by congregation members as "going through" rather than using more clinical language (e.g., depression, anxiety). Luther stated, "There's someone in the congregation all the time that is going through. That's what we call it - going through. And then there's someone that's going through [and] don't even know they're going through."

\section{Causes of Mental Health Issues}

There were no general responses in this domain; rather, categories were either typical or variant (see Table 2). Most often, it seemed that participants spoke about spiritual and social causes of mental health issues, focusing on the importance of relationships both with God and humankind. When participants discussed causes in conjunction with one another (e.g., spiritual and social), we grouped them in the complex category. In other words, complex coping involved an integrative approach in which multiple forms of coping (i.e., biological, psychological, spiritual, social) were enacted together, rather than separately. Five participants attributed anxiety and depression to spiritual causes. This was the most frequent response. For example, Luther stated,

One of the greatest stress or mental health is fear. That's what the enemy uses. That's his number one weapon. That's his number one key. That's his number one everything that he uses to defeat us. He uses it to take away our confidence. People are afraid of what might happen.

When four participants mentioned social spheres of influence as contributors to mental health issues, they emphasized relationships and how people attempt to conform to expectations from society, family, and friends. Jimmy identified isolation and a lack of social support as a primary reason that people suffer from depression. Only one participant mentioned biological factors as a distinct contributor to mental health issues. Two participants named complex (i.e., combination of two or more influences) causes. When other participants mentioned biological factors, they were included as a part of other spheres of influence (e.g., spiritual) and were included in the complex category.

\section{Coping With Mental Health Issues}

In this third domain, participants discussed their beliefs about various ways to cope with mental health issues. Participants identified spiritual, psychological, social, and complex forms of coping. When coping methods were discussed in conjunction with one another, we grouped them in the complex category. Participants also differentiated between adaptive and maladaptive forms of coping. Two other categories emerged in the data, including a typical response of avoidance as a coping mechanism and a variant idea of personal responsibility of the congregation member in the coping process.

Six participants named spiritual forms of coping as an independent, appropriate form of coping. Even when participants endorsed other forms of coping, spiritual coping seemed to be foundational and primary. Luther stated, "Spiritual coping is more effective when God is used as the first and primary source, rather than an afterthought or backup plan." Participants also seemed to rely a great deal on biblical support and spiritual practices when speaking about spiritual coping. Tyler stated, "Prayer really brings results." 
Only two of the eight participants noted psychological approaches as an independent coping method. When other participants spoke about psychological methods, it was in combination with other coping methods (e.g., spiritual, biological, social) and categorized as complex. Participants seemed to value counseling, but indicated the importance of counselor characteristics (e.g., background) and responsibilities (e.g., sensitivity) in its effectiveness. Furthermore, Thomas spoke about the importance of counselors normalizing a person's experience while demonstrating empathy.

All eight of the participants endorsed complex coping as appropriate when dealing with mental health concerns. Participants were more likely to identify a specific cause of anxiety and depression as spiritual, psychological, or social; however, they were more likely to offer an integrated approach to coping with those issues, regardless of the hypothesized cause. William stated, "Whichever one you may choose out of all the ones that you mentioned, maybe that could start a process; maybe it can't complete the process." Participants acknowledged the spiritual component as necessary, but in many cases insufficient, for coping. Felicia stated,

I can give you scripture; I can pray with you and things of that nature, but I've learned even in my personal life, because of one of my children had some issues, as so really to me, professional help is the answer. Now I like to couple that with the word of God if at all possible.

Participants clearly seemed to draw a distinction between adaptive and maladaptive forms of coping. William added that a crucial element of adaptive coping is giving people autonomy in their recovery process. Similarly, Thomas explained, "Not telling them what to do but pointing them to a good model that works, not saying that this is the only way, but this is a way that worked." All of the participants noted that any form of coping in excess could be considered maladaptive. Many of the participants specifically referred to maladaptive forms of spiritual coping. Scott stated,

I think we overuse the spiritual when we don't face reality, when we come with this pious, "Oh God gonna do it, hallelujah, praise God. Oh God, I know I was in trouble but God gonna do this"... I think it is acted out sometimes through emotional shouting and hollering and that's venting some of frustration and some of that depression.

Participants mentioned other forms of maladaptive coping in addition to maladaptive spiritual coping. Other forms of maladaptive coping included overusing prescribed medication as well as forms of self-medication to cope with pain.

Five participants specified avoidance as a particular form of maladaptive coping, which the research team considered a distinct category. On the basis of the participants' statements, it seems that avoidance is a coping method that could lead to anxiety or depression. All of the participants who discussed avoidance seemed to consider it an unfavorable form of coping that they did not endorse or encourage among their congregants. James stated, "You got some that their families are suggesting that they get counseling and they refuse to do it or they go one time 
and won't go back again because something is said that they didn't want to hear." Scott added, "The most times, the present depression that I be dealing with and that I counsel with is because of some past event, traumatic or shattering experience that they haven't dealt with and they have now begun to culminate and begin to get bigger."

Only three participants spoke about personal responsibility in coping, and thus it is considered a variant category. Participants emphasized the individual's role in successfully coping with and recovering from financial constraints or unemployment. Felicia spoke about a specific member in her church who she believed had successfully coped with a financial crisis when she faced unemployment. Felicia recalled saying, "And my best advice you know, just take the time to reinvent yourself, and do something. Maybe you've got to do something different that you're not used to doing."

All eight participants spoke about their own personal experiences with anxiety and depression, describing times in their lives when they have struggled with worrying or feeling depressed. Thomas explained:

Yeah, I think that if any pastor says that they don't experience a level of anxiety, shoot, even Jesus had, on a regular basis, to steal away to the mountain by himself and pray and that's the recipe, the prescription, to help deal with the pressure or the anxiety that comes along with the vocations.

Additionally, the participants described their own personal coping strategies, which primarily involved social and spiritual supports. Overall, participants disclosed that the role of pastor is taxing, and they often neglect their own personal wellness in caring for members of their congregation. Felicia stated, "And we're the worst. Pastors are the worst. We don't rest. You know?" Only one of the participants, William, stated that he had never worried in his entire life and attributed this to his faith.

\section{Perspectives on Mental Health Services}

In this domain, participants spoke about their perspectives on the mental health delivery systems in their communities. The participants spoke about some personal experiences, either with themselves or their family members, as well as experiences they learned of from congregation members. Two primary categories emerged from this domain-positive experiences and negative experiences. All of the participants noted positive experiences with mental health care providers in their community. Participants seemed to also think highly of professionals with whom they had personal connections. Tyler noted, "God has put mental health people there in our presence that they might assist us as ministers." When participants spoke about referrals outside of the church, they seemed to advocate for Christian counselors as potential resources. Participants seemed to trust Christian counselors. Fewer participants talked about negative experiences with mental health service providers, forming a typical category. Jimmy stated, "Some people just want to put everybody in the same boat." Tyler added, "Some places you cannot send people because of the lack of empathy that the workers provide. It's sad."

\section{African American Experience}


In this domain, participants talked about the African American experience as one that is unique from other racial and ethnic populations. Participants noted how pastoring African Americans is different and requires an understanding of the history and the mindset of that specific population. History and stigma emerged as typical categories within this domain. Contrast emerged as a more variant category and is discussed later.

Four participants seemed to note the unique historical experience of African Americans and the Black Church as important and influential in their role as pastors and responding to mental health concerns. Jimmy explained:

I would say it's difficult because you've got so much history. When you're dealing with African American people, a lot of them over the years are bringing the history into the Christianity. And what I mean by that is that we have to be untaught. We've been taught we won't be nothing, can't have nothing.

Four participants also spoke about the stigma that often is associated with seeking help, specifically for mental health issues, within the African American community. When participants spoke about stigma, it seemed to be on a global, rather than individual, level. In other words, avoidance seemed to be more intrinsically motivated, and stigma seemed to be externally motivated, with African Americans as a whole facing stigma. Scott stated, "As a people, we have just not reached a point of understanding the importance of the professional mental health."

Three of the participants spoke about African American culture and coping strategies as being different from other racial/ethnic groups, comparing them to the majority Caucasian culture. The participants indicated that these differences have implications for African Americans' mental health and treatment, but could also lead to misunderstandings about behavior. William stated, "I know with some Black children that was put in a White environment but the teachers could not relate to their learning skills. So automatically the teachers wanna put them on Ritalin."

\section{On Being a Pastor}

Three of the participants spoke about the complex roles that are expected from pastors. Thus, it is considered variant. Luther spoke about the expectations that are placed on him by his congregation, stating that he is sometimes surprised by the roles that people assume he is qualified to handle. Similarly, even though James is not a father, he described fulfilling the role of surrogate father to members in his church. The participants seemed to suggest that although the roles can be challenging at times, they are often rewarding. The roles that these participants have been asked to fulfill could speak to the needs that are prevalent in African American communities and their specific congregations.

Other participants spoke about recognizing their limitations when providing services and thus finding qualified individuals to attend to congregants' needs. Six of the eight participants cited congregation members' growth and development as highlights of their ministry and rewards of pastoring. Many of the participants had observed parishioners in some sort of emotional pain, who, through the ministry, overcame their distress. Participants seemed to take pride in 
witnessing their congregants' growth. Felicia elaborated, saying "just being able to minister and mentor people to a place of wholeness. That's been rewarding for me."

\section{Discussion}

The majority of participants indicated that they saw congregants with mental health needs often, with the majority specifying every day. This confirms existing literature that many African Americans frequently seek help from their pastors on various mental health issues (Ayalon \& Young, 2005). Existing literature, although scarce, has supported the notion that African American pastors are more likely to endorse spiritual causes of mental health issues, such as depression (Payne, 2009). Specifically, participants in the current investigation cited a lack of faith, spiritual warfare, neglecting the spiritual, unanswered prayers, and demonic influences as possible causes of anxiety and depression. However, Payne (2009) focused exclusively on investigating pastoral beliefs regarding the etiology of depression, whereas the current study investigated other mental health issues and emotional stressors also.

Through this investigation, we are able to provide new information regarding African Americans pastors' views on coping. Specifically, on the basis of results from this study, African American pastors appear to endorse more integrative, holistic coping strategies as ideal. It seems that African American pastors value spiritual coping but recognize its potential to be both adaptive and maladaptive. In particular, participants seemed to suggest that they perceive avoidance as a form of maladaptive spiritual coping that is common and problematic in the Black Church.

With some consistency, pastors spoke of working within their scope of expertise (i.e., primarily spiritual but also practical guidance) and relying on additional resources, both within and outside the church, as needed. Overall, the pastors noted positive experiences with professional mental health care service providers in their community. However, it seems that stigma and the history of African Americans challenge pastors' referral processes for treatment, particularly outside of the church. Researchers have suggested that attitudinal barriers seem to supersede structural barriers (Alvidrez, Snowden, \& Kaiser, 2008; Takeuchi, Leaf, \& Kuo, 1988; U.S. Department of Health and Human Services, 2001). Considering the results from this study, we support this notion, because participants devoted more time discussing how stigma and history affected help seeking compared with other issues, such as insurance and monetary resources.

\section{Limitations}

The current findings must be examined within the context of study limitations. Because of the qualitative research design, the sample was relatively small $(N=8)$ and, accordingly, results should be interpreted with caution. Furthermore, participants were recruited via a nonrandom, purposive sampling method. The participant sample included only one female pastor. It is unclear how this may have specifically affected the results. In addition, the restrictive geographic region and sample size could limit the representativeness of this sample to the population of interest. However, rather than aiming for generalizability, qualitative researchers seek transferability, in which readers are empowered to determine whether they can transfer the findings of this sample to other members of the population (Hays \& Singh, 2011). Additionally, considering the sensitivity of the subject matter, participants could have provided socially desirable answers for purposes of this interview. Finally, because of the variation of church 
membership and staff positions in the church, the participants could have varying levels of interaction with their respective congregations, possibly affecting the results.

Although the research team made efforts (i.e., bracketing) throughout the data collection and analysis process to minimize the effect of research team biases and expectations, it is still possible, because of the nature of qualitative procedures, that the data were affected. At the time of data collection and analysis, all of the research team members were academically affiliated with the same university. All of the members of the research team had similar religious backgrounds. Although bracketing and triangulation strategies (i.e., use of research team) were used to minimize bias, it remains possible that some researcher bias entered into the process.

\section{Implications for Counselors and Counselor Educators}

Findings from this study are indicative of nuances in African American religion and spirituality and messages they could be receiving about mental health and coping from their spiritual leaders. Pastors seemed to value an integration of the biological, psychological, social, and spiritual strategies when treating various mental health issues. Counselors should be mindful of these nuances during the counseling relationship as they formulate client conceptualizations and treatment recommendations. Any statement or act from a counselor perceived by the client as demeaning their pastor likely will hurt, if not destroy, the therapeutic alliance.

Cashwell and Watts (2010) and Puchalski and Romer (2000) challenged counselors to be more inclusive and attentive to clients' faith backgrounds. Thus, counselor educators have an opportunity to be more intentional when teaching counselors-in-training about honoring and integrating clients' spiritual backgrounds. One vehicle for integrating spirituality within the counseling curriculum is to teach the spirituality competencies developed by the Association for Spiritual, Ethical, and Religious Values in Counseling (2009; Cashwell \& Watts,2010). These competencies highlight the impetus of respectfully integrating client spirituality into counseling (Cashwell \& Young, 2011) and offer counselors a framework to do so effectively.

Consistently, African Americans are underrepresented in secular counseling help-seeking populations (Ayalon \& Young, 2005). Perhaps this is grounded in our finding that pastors identify Christian counselors as the most competent and trustworthy in providing services to their parishioners. It is important to remember that the term Christian counselor includes practitioners with varying degrees of training, beliefs, and values. In some cases, then, there may be potential value conflicts with the American Counseling Association (ACA) Code of Ethics (ACA, 2014). Generally, participants seemed to have favorable opinions of counseling and saw a need for professional services for congregation members. Thus, counselors have an opportunity to form collaborations with local pastors in their community; however, because pastors seemed to be selective when referring congregation members outside of the church, counselors should be mindful of the importance of building relationships with pastors in order to form trust. One way counselors could build these relationships is to increase mental health and outreach programming in the community, potentially partnering with local Black churches as hosts for these programs.

\section{Future Research}


In the future, it seems important to include mixed-methods or quantitative research methodologies, as well as larger and more diverse samples to replicate the current study. In particular, more female senior pastors need to be included in future participant samples. Future researchers could conduct studies to examine how African American history has influenced current help-seeking behaviors. Also, only one participant (Thomas) mentioned suicide as an issue that needs further investigating in African American communities. In fact, Jimmy was the only other participant to reference suicide and said it was more common in Caucasian communities but not characteristic of African Americans. Given this dichotomy, future researchers could conduct more investigations on pastors' attitudes and experiences with suicide in their congregations.

\section{Conclusion}

Counselors seek to provide effective services to people from various backgrounds and life experiences. The results from this study provide more information about African American pastors' influence on help seeking and beliefs about psychological and spiritual coping. Additional research is needed to better inform best practices in responding to the mental health needs within the African American community.

\section{References}

Alvidrez, J., Snowden, L. R., \& Kaiser, D. M. (2008). The experience of stigma among Black mental health consumers. Journal of Health Care for the Poor and Underserved, 19, 874-893. doi:10.1353/hpu.0.0058

American Counseling Association. (2014). ACA code of ethics. Alexandria, VA: Author.

Andrews, S. L., Stefurak, J. T., \& Mehta, S. (2011). Between a rock and a hard place? Locus of control, religious problem-solving and psychological help-seeking. Mental Health, Religion, \& Culture, 14, 37-41.

Association for Spiritual, Ethical, and Religious Values in Counseling. (2009). Competencies for addressing spiritual and religious issues in counseling. Alexandria, VA: Author.

Awosan, C. I., Sandberg, J. G., \& Hall, C. A. (2011). Understanding the experience of Black clients in marriage and family therapy.Journal of Marital and Family Therapy, 37, 153 -168 .

Ayalon, L., \& Young, M. A. (2005). Racial group differences in help-seeking behaviors. The Journal of Social Psychology, 145,391-403.

Banyard, V. L., \& Miller, K. E. (1998). The powerful potential of qualitative research for community psychology. American Journal of Community Psychology, 26, 485-505.

Burkard, A. W., Knox, S., \& Hill, C. E. (2012). Considerations related to culture in consensual qualitative research. In C. E. Hill (Ed.),Consensual qualitative research: A practical resource investigating social phenomena (pp. 83-102). Washington, DC: American Psychological Association. 
Buser, J. K. (2009). Treatment-seeking disparity between African Americans and Whites: Attitudes toward treatment, coping resources, and racism. Journal of Multicultural Counseling and Development, 37, 94-105.

Cashwell, C. S., \& Watts, R. E. (2010). The new ASERVIC competencies for addressing spiritual and religious issues in counseling.Counseling and Values, 55, 2-5.

Cashwell, C. S., \& Young, J. S. (2011). Diagnosis and treatment. In C. S. Cashwell \& J. S. Young (Eds.), Integrating spirituality and religion into counseling: A guide to competent practice (pp. 163-182). Alexandria, VA: American Counseling Association.

Crook-Lyon, R. E., Goates-Jones, M. K., \& Hill, C. E. (2012). Getting started. In C. E. Hill (Ed.), Consensual qualitative research: A practical resource investigating social phenomena (pp. 71-82). Washington, DC: American Psychological Association.

Douglas, K. B., \& Hopson, R. E. (2001). Understanding the Black church: The dynamics of change. The Journal of Religious Thought,56/57, 95-103.

Farris, K. (2006). The role of African-American pastors in mental health care. Journal of Human Behavior in Social Environment, 14,159-182.

Freeman, M., deMarrais, K., Preissle, J., Roulston, K., \& St. Pierre, E. A. (2007). Standards of evidence in qualitative research: An incitement to discourse. Educational Researcher, 36, 25-32.

Gilkes, C. T. (1980). The Black church as a therapeutic community: Suggested areas for research into the Black religious experience.Journal of the Interdenominational Theological Center, 8, 29-44.

Hays, D. G., \& Singh, A. A. (2011). Qualitative inquiry in clinical and educational settings. New York, NY: Guilford Press.

Heppner, P. P., \& Heppner, M. J. (2004). Writing and publishing your thesis, dissertation, and research. Belmont, CA: Thompson Brooks/Cole.

Heppner, P. P., Wampold, B. E., \& Kivlighan, D. M. (2008). Research design in counseling. Belmont, CA: Thomson Brooks/Cole.

Hill, C. E. (2012). Consensual qualitative research: A practical resource for investigating social phenomena. Washington, DC: American Psychological Association.

Hill, C. E., Knox, S., Thompson, B. J., Williams, E. N., Hess, S. A., \& Ladany, N. (2005). Consensual qualitative research: An update.Journal of Counseling Psychology, 52, 196-205.

Hill, C. E., Thompson, B. J., \& Williams, E. N. (1997). A guide to conducting consensual qualitative research. The Counseling Psychologist, 25, 517-572. 
Hill, C. E., \& Williams, E. N. (2012). The sample. In C. E. Hill (Ed.), Consensual qualitative research: A practical resource investigating social phenomena (pp. 71-82) Washington, DC: American Psychological Association.

Kane, M. N., \& Green, D. (2009). Help-seeking from mental health professionals or clergy: Perceptions of university students. Journal of Spirituality in Mental Health, 11, 290-311.

Ladany, N., Thompson, B. J., \& Hill, C. E. (2012). Cross-analysis. In C. E. Hill (Ed.), Consensual qualitative research: A practical resource investigating social phenomena (pp. 117-134) Washington, DC: American Psychological Association.

Laurie, A., \& Neimeyer, R. A. (2008). African Americans in bereavement: Grief as a function of ethnicity. Omega, 57, 173-193.

Lincoln, C. E., \& Mamiya, L. H. (1990). The Black Church in the African American experience. Durham, NC: Duke University Press.

Mitchell, J. S., \& Ronzio, C. R. (2011). Violence and other stressful life events as triggers of depression and anxiety: What psychological resources protect African American mothers. Maternal and Child Health Journal, 15, 1272-1281. doi:10.1007/s10995-010$\underline{0668-6 .}$.

Murry, V. M., Heflinger, C. A., Suiter, S. V., \& Brody, G. H. (2011). Examining perceptions about mental health care and help-seeking among rural African American families of adolescents. Journal of Youth and Adolescence, 40, 1118-1131.

Newhill, C. E., \& Harris, D. (2007). African American consumers' perceptions of racial disparities in mental health services. Social Work in Public Health, 23, 107-124.

Payne, J. S. (2008). "Saints don't cry": Exploring messages surrounding depression and mental health treatment as expressed by African-American Pentecostal preachers. Journal of African American Studies, 12, 215-228.

Payne, J. S. (2009). Variations in pastors' perceptions of the etiology of depression by race and religious affiliation. Community Mental Health, 4, 355-365. doi:10.1007/s10597-0099210-y

Pew Research Center. (2009, January). A religious portrait of African Americans. Washington, DC: Pew Research Center.

Pinn, A. B. (2010). Understanding and transforming the Black Church. Eugene, OR: Cascade Books. 
Puchalski, C., \& Romer, A. L. (2000). Taking a spiritual history allows clinicians to understand patients more fully. Journal of Palliative Medicine, 3, 129-137.

Smith, S. H. (2002). "Fret no more my child ... for I'm all over heaven all day": Religious beliefs in the bereavement of African American middle-aged daughters coping with the death of an elderly mother. Death Studies, 26, 309-323.

Stahl, J. V., Taylor, N. E., \& Hill, C. E. (2012). The sample. In C. E. Hill (Ed.), Consensual qualitative research: A practical resource investigating social phenomena (pp. 71 -82). Washington, DC: American Psychological Association.

Takeuchi, T. T., Leaf, P. J., \& Kuo, H. S. (1988). Ethnic differences in the perception of barriers to help-seeking. Social Psychiatry and Psychiatric Epidemiology, 2, 115-120.

Thompson, B. J., Vivino, B. L., \& Hill, C. E. (2012). Coding the data: Domains and core ideas. In C. E. Hill (Ed.), Consensual qualitative research: A practical resource investigating social phenomena (pp. 103-116). Washington, DC: American Psychological Association.

Townes, D. L., Chavez-Korell, S., \& Cunningham, N. J. (2009). Reexamining the relationships between racial identity, cultural mistrust, help-seeking attitudes, and preference for a Black counselor. Journal of Counseling Psychology, 56, 330-33

U.S. Department of Health and Human Services. (2001). Mental health: Culture, race, and ethnicity-A supplement to mental health: A report of the Surgeon General. Rockville, MD: U.S. Department of Health and Human Services, Substance Abuse and Mental Health Services Administration, Center for Mental Health Services.

U.S. Department of Health and Human Services. (2010). Health, United States, 2010: With special feature on death and dying.Hyattsville, MD: National Center for Health Statistics.

Watson, D. W., Bisesi, L., Tanamly, S., Sim, T., Branch, C. A., \& Williams, E. (2003). The role of small and medium-sized African-American churches in promoting healthy life styles. Journal of Religion and Health, 42, 191-200.

Welch, M. (2010). Tell me what your God look like. (Unpublished doctoral dissertation). Greensboro, NC: The University of North Carolina at Greensboro.

Williams, E. N., \& Hill, C. E. (2012). Establishing trustworthiness in consensual qualitative research. In C. E. Hill (Ed.), Consensual qualitative research: A practical resource investigating social phenomena (pp. 175-185). Washington, DC: American Psychological Association. 
Williams, E. N., \& Morrow, S. L. (2009). Achieving trustworthiness in qualitative research: A pan-paradigmatic perspective.Psychotherapy Research, 19, 576-582. doi: $10.1080 / 10503300802702113$

Youman, K., Drapalski, A., Stuewig, J., Bagley, K., \& Tangney, J. (2010). Race differences in psychopathology and disparities in treatment seeking: Community and jail-based treatment-seeking patterns. Psychological Services, 7, 11-26. 